\title{
O CUIDADO COMO CONCEITO ARTICULADOR DE UMA NOVA RELAÇÃO ENTRE FILOSOFIA E PEDAGOGIA*
}

\author{
Cláudio Almir Dalbosco*
}

\begin{abstract}
RESUMO: O artigo reconstrói brevemente, em sua primeira parte, a situação de dependência histórica da pedagogia, primeiro em relação à filosofia e, depois, às ciências, para mostrar que um dos resultados de tal dependência é a incorporação, no universo do discurso pedagógico, daquela mesma tendência, presente de modo geral tanto no discurso filosófico como científico, de objetificação do ser humano por meio de sua epistemologização ou eticização. Na segunda parte, recorre ao pensamento heideggeriana de Ser e Tempo e sua crítica à metafísica clássica e à ciência moderna, com o intuito de abalizar um arsenal conceitual produtivo à pedagogia, para que ela possa repensar-se a si mesma. Em que pese todas as dificuldades teóricas intrínsecas ao projeto de extrair desdobramentos pedagógicos desta obra, o conceito de cuidado (Sorge) como tríplice dimensão articulada estruturalmente constitui o fio condutor deste arsenal.
\end{abstract}

Palavras-chave: Pedagogia. Filosofia. Ciência. Ação pedagógica. Ser-aí e cuidado.

\section{CARE as a REgulating CONCEPT OF A NEW RELATIONSHIP BETWEEN PHILOSOPHY AND PEDAGOGY}

ABSTRACT: The first part of this paper briefly rebuilds the situation of historical dependency of pedagogy: first on philosophy and later on science. It thus shows that one of the results of such a dependency has been to incorporate in the pedagogical speech universe the same trend, generally present in both the philosophical and

\footnotetext{
* Uma versão resumida deste ensaio, com o título "Racionalidade e formação", foi apresentada no II Seminário Internacional sobre Filosofia e Educação: Racionalidade e Tolerância, realizado em outubro de 2005 na Universidade de Passo Fundo (RS).

** Doutor em Filosofia pela Universität Kassel (Alemanha) e professor do Curso de Filosofia e do Programa de Pós-Graduação em Educação da Universidade de Passo Fundo (UpF/RS). E-mail:vcdalbosco@hotmail.com
} 
the scientific speech, that objectivizes the human beings through their epistemologization or ethicization. Its second part resorts to Heidegger's thought in Being and Time and his criticism of classical metaphysics and modern science in order to establish a productive conceptual arsenal for pedagogy so that it may rethink itself. In spite of all the theoretical hardships intrinsic to the project of extracting pedagogical deployments from this work, the concept of care (Sorge) as a structurally articulated threefold dimension composes the leading thread of this arsenal.

Key words: Pedagogy. Philosophy. Science. Pedagogical action. Beingthere and care.

\section{Introdução}

$\mathscr{P}$

rocessos formativo-educacionais não ocorrem sem recurso a um conceito de racionalidade. A questão torna-se complexa, no entanto, quando se pergunta tanto pelo conteúdo de tais processos quanto pelos tipos de racionalidade que os sustentam. Concomitantemente a isto, a relação entre processos formativos e tipos de racionalidade conduz, em última análise, à reflexão sobre a relação entre filosofia, ciência e pedagogia e sobre a predominância de tipos objetificados de racionalidade filosófico-científica sobre processos pedagógicos.

Neste contexto, uma observação atenta sobre a história da pedagogia mostra o predomínio tanto de enfoques epistemológicos quanto éticos no trato de questões referentes à educação. Por enfoque epistemológico entendo o emprego da racionalidade teórica que, mesmo quando busca ser crítica em relação a qualquer forma de reducionismo, estabelece seus critérios de validade inspirada nos ideais de objetividade provindos da episteme moderna, sobretudo do modelo físico-matemático. Dessa forma, a epistemologia contemporânea e, de modo especial, a epistemologia moderna, por basear-se num modelo representacional de uma racionalidade calculista que busca dominar e controlar o mundo que está a sua volta, encontram dificuldades de fugir do modelo sujeito e objeto que a tem caracterizado. De outra parte, o enfoque ético caracteriza-se, de modo geral, pela tentativa de justificar um emprego racional-prático da ação humana, sem poder garantir muitas vezes sua autonomia em relação ao emprego teórico da razão. Diante da predominância de um ou de outro destes dois enfoques, o que se tem mostra- 
do problemático para se pensar processos formativo-educacionais é a ausência de uma tematização questionadora das compreensões de ser humano, que sustentam tanto os enfoques epistemológicos como éticos.

Com as afirmações feitas acima é possível estabelecer duas proposições: a) a indispensabilidade do conceito de ser humano e de pessoa humana para se tratar de questóes diretamente relacionadas aos amplos processos humanos de formação e de educação e; b) a incapacidade de enfoques epistemológicos e éticos reduzidos de darem conta de um conceito amplo e problematizador de ser humano. Estas afirmações tornam evidente o fato de que, ao se tratar de processos formativo-educacionais, epistemologia e ética precisam, para sua sustentação, de uma antropologia filosófica. Sendo assim, a questão que se coloca é a de saber que traços de uma antropologia filosófica teriam mais condições de justificar de modo problematizador processos formativo-educacionais.

Esta questão não pode ser respondida no contexto deste pequeno ensaio e, certamente, também não poderia receber uma resposta definitiva nem mesmo no âmbito de um grande tratado. De qualquer modo, vou traçar, inspirando-me em algumas considerações heideggerianas de Sein und Zeit (Ser e Tempo), um breve diagnóstico de alguns aspectos da situação atual da pedagogia para, em seguida, esboçar uma perspectiva geral de tratamento de questões resultantes de tal diagnóstico. Minha hipótese geral é a de que a reflexão acerca dos fragmentos de uma antropologia existencial, apresentada por Heidegger em Sein und Zeit, abre espaço à crítica aos pressupostos metafísicos tradicionais e, simultaneamente, aos pressupostos positivistas que estão subjacentes ao "fazer pedagógico" cotidiano, aos planos políticos pedagógicos e, de modo mais amplo, às teorias educativas, mesmo àquelas que têm pretensão crítica. Ou seja, pode-se ver na tarefa preparatória do procedimento desconstrucionista, ${ }^{1}$ executada pacientemente por Heidegger nesta obra, um exemplo instrutivo à necessária desconstrução de conceitos que, historicamente, moldaram as concepções de pedagogia e de processos formativo-educacionais da cultural ocidental.

O fato de Heidegger não ter pensado de modo sistemático o conceito de uma antropologia existencial e, tampouco, ter buscado extrair desdobramentos pedagógicos de seu conceito existencialista de ser humano mostra-se como uma dificuldade adicional que, embora não seja menos importante, não impede, no entanto, o confronto da fenomenologia hermenêutica com exigências, problemas e conceitos específicos das 
teorias educativas. Na seqüência, limito-me apenas a delinear alguns pequenos traços desta enorme tarefa de investigar os desdobramentos pedagógicos de Sein und Zeit, tarefa esta que ainda está por ser realizada em sua grande extensão.

Breve diagnóstico da situação atual da pedagogia: o afundamento da dimensão formativo-educacional do ser humano no didatismo pedagógico

Quando questionada a partir da perspectiva existencial, ${ }^{2}$ a ação humana apresenta-se, tanto em seu sentido cotidiano como em seu sentido filosófico, encoberta pelas mais diversas formas de objetificação. ${ }^{3}$ Deste processo não se isenta a própria pedagogia e a prova mais cabal disso é a tendência que marcou o debate entre as teorias educacionais do século XX sobre o estatuto científico do conhecimento pedagógico, pois tal debate é, em certo sentido, um rescaldo tardio da "positivação" da subjetividade moderna. Ao assumir o debate sobre a cientificidade de seu saber, a pedagogia torna-se prisioneira de armadilhas teóricas provindas do reducionismo epistemológico próprio ao ambiente intelectual moderno. Este diagnóstico revela o fato de que também as teorias dedicadas a pensar especificamente a dimensão formativo-educacional do ser humano não conseguiram livrar-se inteiramente do predomínio da epistemologia cientificizada, que invadiu todas as áreas do conhecimento humano. Tal predomínio mostra que mesmo iniciativas epistemológicas mais promissoras, como as de origem dialética, interacionista, histórico-cultural e intersubjetivista, podem se tornar, na maioria das vezes e contra a sua própria vontade, prisioneiras da grande dualidade metafísica ocidental entre corpo e alma e sua correspondente versão epistemológica do modelo representacional dicotômico sujeito-objeto. A armadilha teórica contida em tais iniciativas conduz para enormes incongruências, uma vez que, ao produzirem justificativas epistemológicas sofisticadas da interação sujeito-objeto, não conseguem se livrar desta dualidade para pensar a relação formativo-educacional que se estabelece entre seres humanos.

Para ilustrar esta perspectiva, gostaria de me reportar, brevemente, a uma das contribuições mais significativas do século XX para o campo pedagógico. Refiro-me aqui às inúmeras pesquisas sobre a psicogênese do desenvolvimento infantil realizadas por Piaget, com base 
em sua epistemologia genética. O descompasso verificado entre o conceito de estrutura cognitiva presente em seus escritos inicias e aquele que predomina nos escritos de maturidade, sustentado pelo modelo epistemológico de cunho biológico-cibernético, mostra uma mudança significativa no curso de suas investigações. Piaget pensa o desenvolvimento da estrutura cognitivo-moral da criança como um processo interativo baseado num conceito determinado de ação. No período inicial, predomina um conceito de ação pensado a partir da relação entre pares da mesma idade (crianças), sendo considerada a ação do grupo como um fator decisivo não só para a estruturação do pensamento, como, sobretudo, para a constituição da moralidade da criança e, portanto, na formação de valores morais indispensáveis à sua descentração egocêntrica, como os ideais de cooperação e reciprocidade e a inclusão do outro na perspectiva individual. ${ }^{4}$ Mais tarde, como mostra Freitag, Piaget abandona esta linha argumentativa, "introduzindo a idéia do enraizamento do pensamento infantil na ação, no sentido de comportamento, de atuação do organismo sobre objetos do seu meio imediato, no qual os indivíduos assumem o mesmo estatuto de objetos físicos" (Freitag, 1985, p. 29). Seu conceito inicial de ação, pensado a partir da perspectiva interativa entre pares da mesma idade, conseguia atribuir um grau de criatividade autônoma às açôes individuais e, portanto, podia garantir à ação infantil, em certa medida, aquela capacidade especificamente humana de poder iniciar por si mesmo um novo estado, independente dos condicionamentos biológicos e lógicoepistemológicos. No entanto, tal capacidade tende a desaparecer ou a ser fortemente enfraquecida pelo conceito biológico-cibernético do período posterior. Seu modelo psicogenético inicial revelava-se, portanto, muito mais amplo e fecundo à investigação do desenvolvimento moral infantil do que o modelo baseado no organismo que se comporta, "ativado por reflexos internos ou por incentivos externos" e que tem o desenvolvimento de sua inteligência explicado com base na analogia de um prolongamento adaptativo do próprio organismo.

$\mathrm{O}$ que tenho em mente, ao confrontar estes dois momentos de desenvolvimento do pensamento piagetiano, diz respeito às questóes de moralidade. No que se refere às questôes da epistemologia genética e, especificamente, ao seu conceito central de esquemas cognitivos, parece ser plausível a tese, defendida de modo enfático por Lajonquière, de que o Piaget maduro constrói seu edifício epistemológico sem pensar 
numa filiação direta, no sentido de uma "potência causal", entre organismo e inteligência, mas, sim, de modo analógico, no sentido de que as estruturas epistêmicas se derivam de, se apóiam em ou prolongam as regulações orgânicas; isso permite a Piaget não cair, portanto, "nas garras de um vitalismo orgânico e teleológico" (Lajonquière, 1997, p. 135). É no contexto desta interpretação que se deve compreender, segundo o referido autor, o conceito de interação, no qual está implicado não só um novo conceito de sujeito, como também de objeto: a realidade do objeto nunca é empírica, mas intelectual e isso significa dizer, simultaneamente, que ele não é um ente físico e sim "um fragmento de cultura a ser reconstruído" (idem, ibid., p. 137). É a defesa de um "kantismo construtivista", e não "evolutivo", que leva Lajonquière a estas conclusões.

Pois bem, para os nossos propósitos, precisamos nos perguntar pergunta esta não colocada pelo referido autor - o que esta defesa de um kantismo construtivista significa para se pensar o problema do desenvolvimento moral da criança. Mesmo considerando a relativização do peso determinista que poderia estar embutido nas expressões "derivação", "apoio" e "prolongamento", ao se pensar a relação entre estruturas orgânicas e epistêmicas, isso não anula o questionamento de saber se tal relativização não se manteria ainda problemática quando se trata de pensar a relação entre estruturas epistêmicas e estruturas morais? Isso nos conduz então à suspeita de que uma maior liberdade concedida às estruturas epistemológicas, em relação às estruturas orgânicas, não seria suficiente para se apreender a especificidade daquele desenvolvimento cognitivo da criança que assume uma forma especificamente moral. Se entendo bem, a concessão a tal liberdade é feita com base numa certa pressuposição geral errônea, que confunde estrutura epistemológica com estrutura moral, quando não reduz simplesmente a segunda à primeira e, com isso, ignora, por exemplo, os diferentes empregos kantianos da racionalidade que o próprio jovem Piaget levava muito em conta.

Se esta tendência de epistemologização da ação humana ocorre, em certa medida, com uma teoria sofisticada da psicogênese infantil, ela se mostra acentuada em outras posturas teóricas, como é o caso do behaviorismo ortodoxo, ${ }^{5}$ que possui menos força explicativa e base empírica de legitimação do que a epistemologia piagetiana. Tal postura traz em seu bojo teórico uma alta pretensão de objetificação do "comportamento" humano que consiste, em última análise, em tornar ex- 
clusivo o princípio da causalidade no estudo da ação humana. Ou seja, sua base teórica sustenta-se, claramente, no conceito de ação humana como um organismo que se comporta segundo o mecanismo estímuloreação. Desse modo, o ser humano passa a ser compreendido como um efeito que constrói seu mundo e, em última instância, seu Self, por meio de reaçôes aos estímulos postos, internamente, pelos fatores biológicos e psicológicos e, externamente, pelo meio ambiente constituído tanto pela natureza como pela sociedade. Ele se torna entáo prisioneiro daquele circuito de estímulos que se lhe apresentam, perdendo, com isso, sua capacidade de iniciar por si mesmo um novo estado e, portanto, perdendo sua liberdade e, com ela, sua própria capacidade criativa.

As conseqüências disso para se pensar a ação especificamente pedagógica são imensas, se considerarmos ainda mais a tendência imanente a certas teorias educativas, de instrumentalizar tradiçóes epistemológicas em benefício de procedimentos didáticos imediatos. Tal tendência mostra-se profundamente desastrosa para o campo pedagógico numa dupla perspectiva: primeiro, porque, ao se apropriar instrumentalmente das tradições filosóficas, confunde ou simplesmente ignora as forças interpretativas contidas naquelas posiçôes originárias; segundo, porque, ao pretender transpor mecanicamente conceitos e princípios de tais tradições ao âmbito da ação pedagógica, termina por simplificar o sentido humano subjacente em tal ação. Em síntese, na tentativa de instrumentalizar tradiçôes filosóficas e científicas em nome de procedimentos didáticos, esconde-se uma concepção de ser humano como um objeto reduzido ao mecanismo causal e, portanto, passível de ser descrito de forma mensurada e objetificável. Com isso, tem-se, escancaradamente, o ingresso da positivação físico-matemática do processo de teorização no âmbito das teorias pedagógicas e em suas formulações do conceito de ser humano.

Por fim, se a epistemologia moderna tendeu a reduzir o conceito de filosofia ao tratamento de problemas e objetos oriundos da investigação científica, a pedagogia, ao incorporar um conceito positivista de conhecimento, ciência e método, passa a operar com um tipo de racionalidade que tende a objetificar seus próprios temas, conceitos e problemas. Não é difícil perceber que a culminância última deste processo é a própria objetificação da dimensão formativo-educacional do ser humano, que é o tema e o problema central das investigações pedagógicas. Contudo, existe uma outra via de acesso a esta dimensão e que 
repercussões isso traz para o campo pedagógico? Penso que é possível responder afirmativamente a esta pergunta, apresentando a fenomenologia hermenêutica heideggeriana - sobretudo a partir dos conceitos de ser-aí (Dasein), decadência (Verfallen), falatório (Gerede), angústia (Angst) e cuidado (Sorge) de Sein und Zeit - como inauguradora de uma nova antropo$\operatorname{logia}^{6}$ e, portanto, como abertura de um novo horizonte de tematização à pergunta pelo sentido existencial da ação humana. Na seqüência, posso apenas esboçar algumas diretrizes gerais desta empreitada.

Indicações sobre possíveis desdobramentos pedagógicos de Sein und Zeit

\section{Problematização inicial}

Uma primeira dificuldade que se coloca à tarefa de extrair desdobramentos e conseqüências pedagógicas de uma obra da envergadura de Sein und Zeit reside no fato de que Heidegger, além de não ser pedagogo de profissão, escreveu-a especificamente como uma obra filosófica, embora, com isso, não pretendesse bloquear o diálogo com outros campos do conhecimento humano, de modo especial, com as ciências humanas. Considerando isso, nossa tarefa vê-se na eminência de pensar a relação entre filosofia e pedagogia, admitindo como pressuposta a possibilidade de diálogo entre ambas. Mesmo sendo uma pressuposição, ela ampara-se fartamente na própria história da filosofia e, especialmente, na filosofia socrática dos primeiros diálogos platônicos. Sócrates é um dos muitos filósofos que evidenciou com clareza a imbricação entre o exercício da reflexão filosófica e a dimensão pedagógica deste mesmo exercício e o fez com base numa convicção bem determinada: ele estava certo de que a pretensão de inteligibilidade sempre deveria estar posta como condição elementar do diálogo humano e que só poderia ser efetivada na forma de uma relação pedagógica, e isto porque sem a pretensão de cada pessoa de se fazer compreender não haveria como se comunicar com as demais.

É certo que as pretensões filosóficas heideggerianas não têm por meta imediata introduzir novos adeptos à filosofia, mas sim como alvo um público de já iniciados no discurso filosófico. Do ponto de vista metodológico, que é o que nos interessa, ao acompanharmos o percurso do caminho adotado em Sein und Zeit, fica claro que a argumenta- 
ção se eleva do nível ôntico para o nível ontológico de análise do Dasein (ser-aî), embora todas as "descrições ônticas" já são tributárias, desde seu início, de distinções ontológico-existenciais. "O ser-aí é o que onticamente está mais próximo de si mesmo e, ontologicamente, o que está mais distante" (Heidegger, 1967, p. 16). Com isso, temos um ponto de partida que relata a condição intramundana miserável do ser humano, marcada por seu estado decadente e movimentando-se no âmbito do falatório, mas pressupondo como condição de compreensão deste seu estado, uma atitude angustiada que permite o ser humano ver sob outra perspectiva sua própria decadência. Neste sentido, podese dizer que uma das metas centrais da obra é justamente a construção filosófica desta outra perspectiva e, para isso, os conceitos de angústia e cuidado desempenham papel central. De qualquer modo, Heidegger só pode adotar tal ponto de partida porque vê na angústia existencial e na estrutura articuladora de sentido que o cuidado representa a base de sustentação desta nova perspectiva, a qual permite romper com a familiaridade subjacente à perspectiva do mundo cotidiano.

Extrair desdobramentos pedagógicos da estrutura argumentativa filosófica de Sein und Zeit implica, portanto, pressupor a possibilidade de diálogo entre filosofia e pedagogia e a questão central que se põe é a da natureza deste diálogo. Trata-se de uma questão importante, no contexto de nossos propósitos, porque em tal relação está contida, de modo mais específico, a própria problemática envolvida na relação das teorias pedagógicas com a racionalidade filosófica. A relação entre filosofia e pedagogia já se encontra estabelecida, ainda que de modo meio subterrâneo, na própria história da filosofia, bem antes do nascimento da pedagogia como um campo específico de saber. Tal relação fora pensada, de modo geral, a partir do conceito de filosofia como prima ciência, própria ao seu conceito metafísico de um sistema com pretensões universais de tratar do todo englobando tudo o que estava ao seu redor. Resulta disso, em primeiro lugar, uma relação vertical entre ambas, na qual compete à filosofia oferecer os fundamentos à pedagogia. Esta idéia da filosofia como fundamento da educação se encontra não só nos textos dos filósofos, como também e, sobretudo, em muitos manuais de filosofia da educação.

Ora, um dos problemas centrais que emerge desta relação vertical consiste no fato da pedagogia incorporar de modo não crítico em seu discurso a mesma tendência objetificadora que está presente de 
modo dominante na filosofia clássica. Isto é, a pedagogia traz para dentro de seu conteúdo aquela postura filosófica de determinar o que é racional e válido, baseando-se em algo (a Idéia, a Substância ou Deus) que vem de fora da própria racionalidade. Com isso, há a perda de autonomia do pensamento, ocorrendo, segundo o diagnóstico heideggeriano, o esquecimento e a objetificação da pergunta pelo sentido do ser. No caso específico da pedagogia, os problemas pedagógicos passam a ser pensados num contexto eminentemente ontológico, que trata primeiro da definição das "essências" para somente depois tratar da "realidade", fazendo com que não se alcance mais, em última instância, a própria historicidade da ação humana. Um dos exemplos mais claros desta influência da clássica filosofia ontológica no domínio do saber pedagógico mostra-se no conceito de educação infantil: embora a criança não nasça sabendo, ela traz dentro de si uma essência que precisa ser desabrochada pelo trabalho do pedagogo. Mas, tal essência só pode aflorar por meio de uma ação enérgica e disciplinada do pedagogo, uma vez que a criança, quando abandonada aos seus próprios sentimentos, "extravia-se" e não encontra o caminho seguro mediante o qual se torna uma pessoa autônoma. A criança é vista desde o princípio como um pequeno adulto cujo desenvolvimento necessita de uma intervenção constante do adulto.

Este problema ganha novas feições quando a racionalidade filosófica passa a ser diluída progressivamente no procedimento metódicoexperimental da ciência moderna. O que se verifica aí é um cruzamento, no mínimo curioso, entre filosofia e ciência e, com o nascimento do positivismo moderno, aquela pretensão de prima ciência, outrora assumida pela filosofia, migra para dentro da própria ciência. Assim, a episteme de base positivista ${ }^{7}$ passa a ditar os ideais de objetividade e validade a todas as outras formas de conhecimento, incluindo entre elas o próprio saber pedagógico. A relação vertical entre filosofia e pedagogia mostra-se agora na relação entre ciência e pedagogia, provocando a positivação do saber pedagógico. Desse modo, são cada vez mais enfraquecidas aquelas poucas vozes que ainda procuram manter na pedagogia o status de um estudo ou saber, diferenciando-o de um conhecimento científico reduzido a observação e análise do comportamento humano. A positivação da pedagogia - e este é o fato novo - marca a passagem do essencialismo para o experimentalismo, caracterizando assim uma nova postura pedagógica: a criança ao nascer é uma tabula 
rasa que precisa ser preenchida de conteúdo. Não se extrai mais um saber contido interiormente, mas se traz de fora o conteúdo que deve ser assimilado pela própria experiência da criança. De novo, a figura do pedagogo torna-se determinante, uma vez que é ele que está de posse dos conteúdos e que, por isso, deve dominar o processo pedagógico. A postura epistemológica em relação ao essencialismo pode até mudar, mas o procedimento metodológico-pedagógico mantém ainda uma clara base autoritária.

Salta aos olhos, destas breves considerações, uma total dependência da pedagogia à filosofia e à ciência. Jogada nos braços alheios, ela encontra-se em crise, sem identidade, o que faz emergir, com toda a intensidade, por um lado, a questão sobre a natureza e a especificidade de seu próprio conteúdo e, por outro, o caminho mais adequado para buscar sua independização em relação ao objetivismo inerente à filosofia clássica e ao positivismo moderno. Neste ínterim precisamos pontualizar algumas perguntas: Qual é o caminho mais adequado para que a pedagogia possa alcançar sua independência? $\mathrm{O}$ que esta independência pode revelar em termos de novo conteúdo à pedagogia? Por outro lado, uma vez que a busca pela sua autonomia não significa ausência de diálogo com a filosofia e a ciência, que estatuto deve assumir este diálogo?

No contexto desta problemática, interessa-me saber qual é a contribuição da fenomenologia hermenêutica heideggeriana. Isto é, tratase de saber em que sentido Sein und Zeit abre uma possibilidade de se pensar de outro modo a relação entre filosofia e pedagogia, considerando o rompimento que tal obra faz com a tradição filosófica e com a ciência moderna, trazendo consigo a pretensão de inaugurar um novo paradigma. A questão pode ser mais bem precisada da seguinte forma: $\mathrm{O}$ que a crítica heideggeriana à racionalidade objetivista da filosofia clássica e da ciência moderna traz de novo para se romper com a relação vertical, historicamente pensada, primeiro entre filosofia e pedagogia e, depois, entre ciência e pedagogia? Por fim, o que tal crítica póe de exigência à própria pedagogia?

Feito brevemente o diagnóstico sobre a situação atual da pedagogia e lançado o problema, gostaria de indicar, resumidamente, um possível fio condutor para tratá-lo. Ao criticar o modelo representacional subjacente tanto ao discurso filosófico como científico, a fenomenologia hermenêutica de Sein und Zeit abre caminho para uma autocrítica da positivação do discurso assumido pela pedagogia no século XX. Isto é, 
a crítica desenvolvida nesta obra à racionalidade filosófica e científica pode servir como arsenal produtivo para uma autocrítica do próprio saber pedagógico e, simultaneamente, oferecer indicações valiosas à pedagogia, tanto do ponto de vista metodológico como de conteúdo. O detalhamento deste fio condutor exige a escolha e a reconstrução adequada de alguns parágrafos desta obra que possam mostrar os desdobramentos pedagógicos não visualizados pelo próprio Heidegger. ${ }^{8}$

A título de antecipação provisória, o núcleo do argumento pode ser resumido da seguinte forma: a tentativa de mostrar aspectos pedagógicos subjacentes a Sein und Zeit precisa ser remetida à análise da estrutura existencial nuclear do ser-aí (Dasein) e, mais especificamente, à tensão entre as perspectivas do mundo cotidiano e do mundo existencial, entre os aspectos da decadência (Verfallen) e do falatório (Gerede), por um lado, e a angústia (Angst) e o sentido ontológico do cuidado (Sorge), por outro. É no tratamento adequado desta tensão e, ao mesmo tempo, na desconstrução de um modo de vida baseado no falatório e a inserção deste modo de vida nas estruturas ontológicas articuladoras do cuidado, provocada pelo "deixar-se levar" pela angústia, que emergem as teses pedagógicas implícitas em Sein und Zeit e onde repousa, em última instância, a validade da afirmação de que Heidegger inaugura, com esta obra, um novo paradigma na filosofia do século XX. Na seqüência, quero me concentrar no significado filosófico-pedagógico do cuidado.

\section{A tríplice dimensão de articulação estrutural do cuidado e sua significação filosófico-pedagógica}

Chego agora ao ponto nuclear de minha argumentação, o que me exige colocar, imediatamente, a questão sobre o que há de genuinamente filosófico e, ao mesmo tempo, de pedagógico no conceito de cuidado (Sorge) que pode torná-lo um conceito indispensável para se pensar a relação entre filosofia e pedagogia, de uma maneira inteiramente nova em relação àquela maneira apresentada pela filosofia clássica, tanto antiga como moderna. $\mathrm{O}$ aspecto genuinamente filosófico e, ao mesmo tempo, pedagógico do conceito de cuidado reside em sua dimensão de totalidade, revelada pelo modo prático de o homem ser-no-mundo. Neste contexto, os parágrafos 42 e 65 de Ser e Tempo tornam-se indispensáveis para o esclarecimento desta sua dimensão de totalida- 
de. Por isso, façamos uma breve reconstrução de alguns aspectos de seu conteúdo.

Nestes parágrafos ocorre a definição do cuidado como ser do seraí. Mas qual é o significado desta afirmação? O cuidado assume esta condição porque significa a totalidade na qual o ser-aí como ser-nomundo se encontra. Do ponto de vista metodológico, esta condição significa o duplo ponto de vista, ou seja, a dupla perspectiva mediante a qual o ser humano se compreende, adotando a perspectiva cotidiana e existencial. Mas trata-se de uma significação metodológica que, antes de ser epistemológica e ética, é ontológico-existencial. Isso significa dizer que o cuidado revela as condiçōes de possibilidade para se pensar a perspectiva da vida humana afogada na familiaridade do mundo cotidiano, mas somente na medida em que se abre à perspectiva que torna possível a compreensão da própria familiaridade. Por isso que o cuidado, como ser do ser-aí, como sua totalidade e como sua condição ontológico-existencial, significa o modo fundamental de relação com a ação humana, com suas relaçōes pessoais e sociais, numa outra perspectiva que não só a da familiaridade cotidiana. Cuidado diz respeito então a uma atitude, a um modo prático de ser-no-mundo adotado pelo ser humano em relação à sua ação e ao fenômeno da vida em sua totalidade. Por isso, não comporta uma atitude parcial, fragmentada ou recortada da ação humana, que tomasse por base somente uma racionalidade estratégico-procedimental, mas sim um modo de existir que exige do ser-aí uma autocompreensão de sua ação como um acontecimento que abrange a vida humana em sua totalidade. Cuidado exige a ocupação da vida humana consigo mesma e com os outros, cuja própria ocupação deve ter em mente uma perspectiva de integralidade, com a faticidade, a existencialidade e a decadência da ação humana. Portanto, agir de acordo com o cuidado significa viver num momento presente, mas com a consciência da temporalidade, isto é, de pertença a um passado e com capacidade de projetar um horizonte.

Ora, se o cuidado é um modo prático adotado pelo ser humano, a questão que se coloca é como ele opera com este modo prático e qual é a importância disso para sua própria vida? Como totalidade, o cuidado não pode se constituir somente na perspectiva do mundo existencial e, muito menos, só na perspectiva do mundo cotidiano. Ele é constituído por ambos, mas, enquanto modo prático, só permite a compreensão desta dupla perspectiva quando já inserido no mundo existencial e esta sua 
inserção é garantida, como vimos, pelo fenômeno da angústia: uma vez angustiado o ser humano projeta-se na dimensão existencial do cuidado. Como ser do ser-aí, o cuidado é temporalidade. Heidegger formula do seguinte modo sua tese: "A unidade originária da estrutura do cuidado reside na temporalidade" (1967, p. 327). Nela residem também a faticidade, a decadência e a existência, enquanto elementos componentes da tríplice estrutura do cuidado: "A temporalidade possibilita a unidade entre existência, faticidade e decadência e, deste modo, constitui originariamente a totalidade da estrutura do cuidado" (ibid., p. 328).

O cuidado carrega consigo, portanto, a tríplice estrutura da temporalidade e, neste sentido, a própria tríplice estrutura constitutiva do conceito de mundo: decadência, faticidade e existência. Como a faticidade é o ponto de partida tanto da decadência como da existência, então se pode dizer que o cuidado carrega em si a dupla dimensão de mundo, como decadente (que é a dimensão do tempo presente, significando a dimensão da vida humana que transcorre no curso cotidiano) e como mundo existencial (que é a dimensão do tempo futuro, isto é, da vida humana que se projeta à frente do curso cotidiano). Esquematicamente, temos a seguinte tríplice estrutura do cuidado:

$$
\begin{aligned}
& \text { - Já-ser-em—passado_ faticidade } \\
& \text { - Ser-junto das coisas — presente —_ decadência —_ (cuidado) } \\
& \text { - Ser-adiante-de-si-mesmo _ futuro — existencialidade }
\end{aligned}
$$

Com este significado esquemático, representado acima, podemos interpretar que Heidegger quer evidenciar o modo de autocompreensão do ser humano, por meio do qual ele compreende-se como um ser vivendo em um presente que se originou de um passado - do qual ele não teve oportunidade de escolher nem o lugar e nem o momento histórico de seu nascimento - e que caminha em direção a um futuro do qual a única certeza que possui é a de sua morte. Heidegger deixa claro que não há um "nexo originário" ("ursprünglicher Zusammenhang”) entre estas três dimensões e é por isso que elas formam juntas a estrutura do cuidado (ibid., p. 191). Neste contexto, a angústia é a atitude - no sentido de procedimento metodológico -, por meio da qual o ser humano alcança a idéia de temporalidade (e com ela a idéia de historicidade), forçando-o a um ter-que-ser diante da morte, diante de sua fraqueza e de seus limites. Justamente neste contexto é que podemos 
compreender melhor a linguagem de Ser e Tempo de que todo discurso epistemológico já se encontra inserido em um limite, porque se movimenta somente no âmbito do estar-junto-das-coisas, não conseguindo apanhar as dimensões do já-ser-em (dimensão de passado) e do ser-adiante-de-si (dimensão de futuro). Isto é, pelo fato de investigar o âmbito da coisidade, mantendo-se na descrição daquilo que é, a epistemologia não abrange a dimensão fática e nem existencial da ação humana.

É o significado existencial do cuidado que motiva a crítica heideggeriana à epistemologia e é ele também que está na base da guinada central de seu pensamento em relação à tradição filosófica moderna. Ao introduzir o conceito de Dasein e ao considerar o cuidado como seu ser, Heidegger intenciona fazer uma crítica à idéia da subjetividade como fundamento último da justificação: "Através do caráter ontológico-existencial do Dasein, expresso no autocompreender-se do cuidado, ele [Heidegger, CAD.] soube evitar a reprodução da subjetividade como fundamento" (Stein, 1993, p. 121). Isto é, segundo esta interpretação, a novidade heideggeriana reside em apresentar uma transcendentalidade sem sujeito, simplesmente pelo fato de que o Dasein é concebido anteriormente à consciência, passando mesmo a englobá-la: o ser-aí deixa de ser contido pela consciência subjetiva representacional e passa a englobá-la.

Precisamos tornar mais clara esta tese heideggeriana de que o cuidado é o ser do ser-aí. Neste sentido, devemos reter um ponto da análise anterior, mediante o qual se firmou a idéia de que o ser-aí heideggeriano não pode ser mais confundido com aquele conceito de subjetividade que servia de ponto de partida da filosofia moderna; portanto, no contexto heideggeriano, o ser-aí tem uma significação mais ampla. Com esta afirmação nos é permitido concluir que o modo prático do ser-aí, enquanto um ter-que-ser, não pode mais ser entendido só como ato de uma consciência representacional do mundo e, do ponto de vista moral, como um ter-que-obedecer à lei moral no sentido kantiano (Loparic, 2003, p. 47). Embora isso represente uma enorme ruptura com a tradição moderna e, por isso, resume-se em um dos problemas filosóficos centrais de Ser e Tempo, vou considerá-la provisoriamente como pressuposta.

Amparando-me na interpretação de Loparic (2003, p. 11-60), quero dar um passo adiante e associar a compreensão do conceito de cuidado com uma postura ética de responsabilidade do ser humano em relação à integralidade de sua vida e com a perspectiva de mundo como 
totalidade. Loparic vincula o cuidado diretamente com a questão da "voz da consciência". Mas, o ponto problemático desta vinculação pode residir no emprego não desconstruido da expressão "voz da consciência”, uma vez que ela já fora amplamente empregada pela tradição filosófica, tanto por Sócrates, como por Agostinho e Rousseau, para citar apenas três autores. O risco imanente ao emprego desta noção para esclarecer o sentido do conceito de cuidado está, portanto, em fazer voltar pela porta dos fundos o problema que Heidegger quer jogar pela porta da frente. Isto é, a noção de "voz da consciência" não pode mais significar o apelo a uma consciência subjetiva representacional que constitui o mundo a partir de sua autoreferência. Embora Heidegger não leve às últimas conseqüências o seu pensamento sobre este ponto, mantendo sua argumentação em muitos momentos num nível dependente ainda de pressupostos da filosofia moderna, penso que a característica central do ser-com (Mitsein) atribuída ao Dasein torna-se uma referência indispensável para se pensar a "voz da consciência” não como ato instituído por uma consciência solipsista, como se fosse uma mônada fechada em si mesma, mas sim como uma expressão tanto do falatório como do discurso e, em certo sentido, também como expressão de uma ação mediada simbolicamente. ${ }^{9}$

Loparic interpreta Ser e Tempo como uma ética da aceitação incondicional da finitude humana e procura assegurar, no contexto desta interpretação, o nexo entre cuidado e voz da consciência. Brotando da estrutura existencial do Dasein, a ética heideggeriana diz respeito, segundo ele, à pergunta de "como deixar acontecer, estando-aí no mundo, o que tem-que-ser?” (2003, p. 18). Esta pergunta traduz o conteúdo ético central de Ser e Tempo, representando, ao mesmo tempo, uma "desconstrução" ontológico-existencial inovadora do conceito metafísico de dever. $\mathrm{O}$ fato extraordinariamente humano é o de que somos jogados no mundo e, enquanto seres dados, temos-que-ser. Ora, o acesso a este tipo de dadidade (Gegebenheit) é oferecido pelo chamado da voz da consciência, ouvida no silêncio disposto à angústia. Trata-se de uma voz que, segundo Loparic, provém "do nosso cuidado para com o nosso ser, revelando este ser como culpa/dívida, ${ }^{10}$ justamente, portanto, como um ter-que-ser até não poder mais ser, até a morte" (ibid., p. 20).

Como modo prático de o ser humano ser-no-mundo, o cuidado constitui o núcleo ético de Ser e Tempo e também diz respeito, de modo geral, à desconstrução heideggeriana do conceito clássico de dever, pri- 
meiro, porque tem como ponto de partida a faticidade humana constituída por uma existência finita. Segundo, e conectado com o ponto anterior, porque não se refere mais exclusivamente ao fato de ter que seguir a lei moral ou seguir normas, mas, sim, de seguir um chamamento, a saber, o de deixar manifestar-se uma existência finita, buscando compreender o significado disso à vida humana. Desta atitude de compreender "o deixar ser" desdobra-se um novo conceito de ação, o qual não se restringe mais só em produzir efeitos, movendo-se apenas na esfera da ocupação objetual com o mundo, mas em fazer emergir sentidos imanentes ao ser-aí: "Trata-se de um agir por ter-que-agir, que não espera por resultados" (ibid., p. 22). Em síntese, é da tese de que o ser humano é um ser que está em falta, isto é, que é um ser finito que caminha para a morte e que, por isso, é um ser que tem-que-ser-parao-nada que brota, segundo Loparic, a moralidade e, com ela, a própria noção de responsabilidade humana.

$\mathrm{Na}$ seqüência, Loparic argumenta mostrando que a estrutura do existir humano "impóe" a questão do sentido de seu ser e o modo de sua existência concreta constitui-se na resposta àquela questão. Tal estrutura é constituída pela tensão entre as possibilidades mundanas, as quais se movimentam na esfera daquilo que é, e as possibilidades de abertura geradas pela perspectiva do mundo existencial, que tornam concreto ao ser humano o fato dele não pode-ser-mais e, portanto, o fato dele possuir uma existência finita. Significativo desta dinâmica imanente à constituição do ser-aí é que a abertura gera o fenômeno da transcendência, que possibilita ao ser humano a compreensão sobre seu si mesmo mundano. Se interpretarmos que aí reside o conteúdo central da pergunta pelo sentido existencial da vida humana, então somos obrigados também a ver no fenômeno da abertura um sentido filosófico-pedagógico de primeira grandeza. Sem esta abertura e sem a sensibilidade em provocá-la nos envolvidos da relação pedagógica, a pedagogia correria o risco de se mover apenas na esfera de possibilidades do mundo cotidiano e, com isso, permanecer na esfera das vivências sem, contudo, adentrar no fenômeno da existência. Isto significa, em termos de se pensar o papel do pedagogo, que se ele não for afetado pelo "fenômeno da abertura", pode limitar-se a pensar sua prática pedagógica somente de acordo com as possibilidades do mundo cotidiano. $\mathrm{O}$ pedagogo pode movimentar-se muito bem no mundo cotidiano, de modo estrategicamente planejado e ensinar seus educandos também a fazê-lo, mas sem alcançar, no entanto, o nível fun- 
damental que permite conceber os limites e as implicaçóes contidos neste modo estrategicamente planejado de viver. Permanecendo neste nível, o pedagogo exerce seu ofício afogado na familiaridade do mundo cotidiano, desenvolvendo um "fazer pedagógico", sem poder alcançar o âmbito do "agir pedagógico".

Gostaria de voltar-me agora ao esclarecimento da afirmação de que o cuidado, para poder assumir a condição ontológica de ser do ser-aí, precisa assumir a dimensão de totalidade, a qual, por sua vez, contém a dupla perspectiva, ôntica e ontológico-existencial. Este é um ponto importante, porque numa leitura apressada poderíamos ser levados a interpretar o cuidado só da perspectiva existencial e, com isso, mesmo contra a vontade, admitir o ingresso, pela porta dos fundos, do mundo inteligível platônico. No entanto, para que o Dasein possa ser compreendido como temporalidade e possa incluir nela a historicidade, é preciso que o cuidado também seja constituído pela perspectiva do mundo cotidiano e não representar somente a perspectiva do mundo existencial. Esta tese, aparentemente desconcertante, encontra legitimação na própria argumentação heideggeriana, na medida em que Heidegger atribui ao acontecer finito do ser-aí, ao menos, três diferentes projetos de sentido do ser, que se cruzam entre si: os projetos da existencialidade, da instrumentalidade e da presentidade. O ponto crucial aí é o de que em cada um destes projetos emerge um sentido preciso de cuidado, entendido como atitude de se ocupar consigo mesmo, com os outros e com as coisas. Desse modo, o cuidado na esfera da instrumentalidade diz respeito ao ter-que-trabalhar; na presentidade, ao ter que considerar os entes como objetos presentes e, por fim, na esfera da existencialidade, o cuidado refere-se ao ter-que-ser como estar-aí-no-mundo na companhia de outros. Embora seja constituído por estas três esferas, é na da existencialidade que reside a condição das outras duas.

Espero ter delineado até aqui aspectos centrais da antropologia existencial heideggeriana. Antes de concluir, tratando de alguns desdobramentos pedagógicos, vou resumir, em forma de tese, alguns destes aspectos:

a) A pergunta sobre o sentido do ser é delimitada pela pergunta sobre o sentido do Dasein, o qual, enquanto um ser que se compreende, tem a possibilidade de repor novamente a pergunta pelo sentido do ser. (Aqui residiria a boa circularidade!). 
b) Dasein é o ser humano que se compreende a si mesmo e, enquanto tal, é um ser de possibilidades tanto à impropriedade como à propriedade. Isto é, possui um poder-ser que pode voltar-se tanto à inautenticidade como à autenticidade.

c) Enquanto encoberto pelas amarras do mundo cotidiano, permanecendo submerso ao mundo das ocupações, o ser humano caracteriza-se pela decadência e pelo falatório.

d) No entanto, por ele ser constituído também pela angústia, pode assumir a perspectiva do mundo existencial e, com ele, distanciar-se criticamente da perspectiva do mundo cotidiano e de sua ocupação rotineira e instrumental com as coisas.

e) A angústia, como "disposição de abertura", descortina ao ser humano o modo prático do cuidado. Cuidado não significa outra coisa, em seu sentido ontológico-existencial, do que a compreensão da vida humana em sua dimensão de totalidade, enquanto decadência, faticidade e existencialidade.

f) Por fim, a tese mais forte da antropologia existencial consiste na afirmação da tensão constitutiva do Dasein, evidenciada na tríplice dimensão articulada estruturalmente do cuidado. Tratase de uma tensão, porque, sem que o ser humano possa se desfazer dela, sua tríplice dimensão constitui a temporalidade e, com ela, a finitude do Dasein.

Para concluir, gostaria ainda de fazer uma consideração sobre o significado pedagógico da tríplice dimensão articulada estruturalmente. ${ }^{11}$ É ela que empurra o ser humano a ver sua condição finita a partir de uma dupla perspectiva: a da familiaridade e tranqüilidade de sua ação imersa no mundo cotidiano, no qual ela se encontra sob o domínio da decadência e do falatório; e a da ação angustiada existencialmente que, ao por o ser humano na posição de poder ouvir o clamor de sua consciência, ${ }^{12}$ assume o cuidado como modo prático de enfrentar o fato de que é um ser jogado no mundo e que caminha para a morte. Cuidado é, neste sentido, a dimensão existencial da ação assumida pelo ser humano para, consciente de sua temporalidade e historicidade, se formar a si mesmo por meio da postura dialógico-compreensiva com os outros e com as coisas. Mas este formar-se a si mesmo só adquire sentido na medida em que o ser humano se descobre e se 
autocompreende como um ser incompleto que, enquanto tal, precisa buscar permanentemente sua completude, mesmo sabendo que jamais pode alcançá-la definitivamente. Central, neste contexto - e este aspecto constitui o sentido pedagógico do cuidado -, é a idéia de que a ação humana orientada pelo cuidado precisa levar em conta a própria dimensão de incompletude do ser humano. Transformando-se em consciência angustiada, a ação humana, baseada no cuidado, enfrenta sua mais cruel e, ao mesmo tempo, mais humana dimensão de sua faticidade, a saber, de que é gerada (movimentada) por um ser, o ser humano, que é incompleto e que, por sê-lo, caminha para a morte.

O que está implicado na estrutura existencial do ser-aí como cuidado é - e isso assume também significações relevantes ao campo pedagógico - a compreensão do ser humano não mais como uma substancialidade, mas sim como uma acontecência (Geschichtlichkeit) que exige dele, antes de tudo, assumir autentica e radicalmente sua incompletude e, portanto, sua historicidade. Ora, com esta linha de pensamento Heidegger pretende deixar claro que o aspecto fundamental da vida humana reside no fato do ser humano "ser um acontecente" (Loparic, 1995, p. 49). Este traço de uma nova antropologia abre a possibilidade para se visualizar melhor as primeiras e mais importantes tarefas do pedagogo (quer seja pai, mãe, professor ou professora), a saber, a de não intervir autoritariamente no desenvolvimento cognitivo e moral da criança, mas contribuir para que aspectos deste seu desenvolvimento simplesmente aconteçam.

A compreensão do ser-aí como acontecência justifica, do ponto de vista antropológico-existencial, uma dimensão da ação humana que precisa levar em conta a contingência e a transitoriedade como seu aspecto constitutivo. E isto significa, especificamente do ponto de vista pedagógico, que a construção do "essencial" no desenvolvimento cognitivo e moral da criança deve partir do fato de que ela também é constituída por uma dimensão decadente que pode mantêla, caso não seja enfrentado pedagogicamente, no âmbito do falatório. No entanto, uma pedagogia aberta ao fato profundamente humano do contingente pode descortinar um processo formativo-educacional ao ser humano que ultrapasse simplesmente uma pedagogia do falatório, a qual se encontra enraizada, de modo geral, em uma concepção dogmática de ser humano. Ao contrário da metafísica aristotélica, a pedagogia com inspiração na fenomenologia hermenêutica de 


\section{Ser e Tempo deve ser concebida como "ciência do acidental" e, talvez por isso, possa enfrentar mais adequadamente o problema do desen- volvimento cognitivo, moral e estético da criança.}

\section{Recebido em abril de 2006 e aprovado em setembro de 2006.}

\section{Notas}

1. No parágrafo 6 de Sein und Zeit Heidegger explica em que consistirá, em linhas gerais, sua tarefa de Destruktion da história da ontologia, tendo como alvo crítico a redução do sentido do ser ao sentido da presença, provocando com isso um processo de "enticização" do ser. Com a pretendida cautela de evitar transformar o passado em um nada negativo, ele elabora o conceito de Dasein como contraponto ao processo de enticização do ser, visando preservar aspectos que julga produtivos da história da ontologia. Mas, embora seja preparada pela analítica existencial e pela analítica da temporalidade, a tarefa desconstrucionista só será levada efetivamente adiante com a história do ser do segundo Heidegger. Isso faz surgir, então, do ponto de vista do desenvolvimento sistemático da filosofia heideggeriana, a interessante questão sobre as possíveis transformações que o esboço de uma antropologia existencial assume no confronto entre o pensamento do primeiro e do segundo Heidegger: Qual é o significado que a antropologia existencial assume depois da Kehre (viravolta) e o que representa tal significado quando confrontado com aquele esboço derivado dos existenciais analíticos do Dasein? A presente exposição não tem como objeto discutir esta questão, mas, sim, como já indicado, retomará, na última parte, idéias referentes ao esboço da antropologia existencial delineado em Sein und Zeit.

2. Por questionamento existencial entende-se, no sentido heideggeriano de Sein und Zeit, um questionamento amparado na angústia, assumindo a estrutura ontológica do cuidado como modo prático de o ser humano ser-no-mundo. Ele pressupōe, portanto, a perspectiva ontológica que implica a ruptura com a familiaridade e aparente tranqüilidade da perspectiva do mundo cotidiano. O questionamento existencial tem sua procedência no próprio conceito de Existência, o qual certamente é um dos conceitos mais importantes e, ao mesmo tempo, mais difíceis de Sein und Zeit. Seu significado mais importante é o da existência como possibilidade. Isto é, partindo do fato de que o homem é um ser jogado que caminha para a morte, Heidegger concebe sua existência como poder-ser numa dupla direção, à inautenticidade (impropriedade) e à autenticidade (propriedade). Neste contexto, assumir com radicalidade a existência significa, segundo ele, buscar ser autêntico, mesmo sabendo que esta autenticidade empurra-o à morte ou que ela é a própria morte. Assim afirma ele no parágrafo 45: "Determinamos a idéia de existência como o poder-ser que se compreende, no qual está em jogo seu próprio ser” (Heidegger, 1967, p. 233). A tradução das passagens citadas de Ser e Tempo são de minha própria autoria.

3. Objetificação é um conceito central aos meus propósitos de esboçar uma pedagogia hermenêutica a partir de Ser e Tempo. Os dois interlocutores decisivos de Heidegger, quando ele trata das diferentes formas de objetificação que a cultura ocidental assumiu, historicamente, são a metafísica clássica e a ciência moderna. Para ele, há um processo semelhante no tipo de racionalidade adotado por estas duas formas de conhecimento, que culmina no esquecimento da pergunta pelo sentido do ser e do sentido da própria existência humana. Objetificação significa, no sentido heideggeriano, a "enticização" do ser e a sua transformação posterior em objeto. Na linguagem da antropologia existencial, objetificação sig-

Educ. Soc., Campinas, vol. 27, n. 97, p. 1113-1135, set./dez. 2006 
nifica então a própria transformação do homem em um ente presente no mundo e na sua simultânea representação em forma de objeto.

4. Para uma leitura dos escritos iniciais de Piaget nesta direção, ver, sobretudo, Youniss (1994). Este autor interpreta Piaget com base na tese geral de que o ser humano é um sujeito agente que constrói o significado de sua ação por meio de seu relacionamento com o mundo objetivo (natureza) e social (outros seres humanos, suas regras e instituiçôes). Entretanto, é por meio da relação com pares da mesma idade que a criança não só descobre relacionamentos simétricos como os torna central para a construção de seu Self. Relacionamentos com pares da mesma idade conduzem à reciprocidade simétrica e, por isso, apresentam tendencialmente uma boa perspectiva de construírem relacionamentos sociais solidários (Youniss, 1994, p. 154-158).

5. Por behaviorismo ortodoxo entendo aquele desenvolvido principalmente por Watson nas primeiras décadas do século XX.

6. Embora Heidegger não fundamente sistematicamente uma antropologia existencial em Sein und Zeit, ela está subjacente à dupla perspectiva geral contida nesta obra: como "desconstrução" do sentido clássico de ontologia e como fundação da ontologia fundamental, a qual, com a pretensão de trazer consigo um novo sentido de ontologia, exige adotar, como ponto de partida, a tematização do ser-aí (Dasein) como ente que se compreende e, ao se autocompreender, pode perguntar pelo próprio sentido do ser. Portanto, sentido ontológico tem a ver, em Heidegger, com o modo prático de o homem ser-no-mundo e está intimamente relacionado com uma reflexão antropológica de caráter existencial. Sobre isso, ver Pöggeler, 1999, p. 174-186.

7. Por episteme de base positivista entendo aqui aquele modelo de racionalidade físico-matemático que tem nos ideais de observação, verificação, mensuração e regularidade os critérios de validade do conhecimento.

8. Ocupo-me sistematicamente com este propósito no trabalho, em elaboração, intitulado provisoriamente de Pedagogia hermenêutica: dimensōes da racionalidade pedagógica em Ser e Tempo.

9. Certamente, Heidegger não dá o passo decisivo, em Ser e Tempo, como dará G. H. Mead, quase no mesmo período histórico, de compreender a ação humana como uma ação mediada simbolicamente. No entanto, com ajuda de aspectos do interacionismo simbólico e da própria filosofia analítica da linguagem se poderia empreender o esforço em interpretar o falatório e o discurso, como constitutivos do ser-aí na direção de uma ação mediada por símbolos.

10. A tradução de Schuld por culpa/dívida, como o faz Loparic nesta passagem, mantém um peso demasiadamente teológico e, por isso, deixa tal expressão ainda carregada de um sentido ôntico não pensado por Heidegger ao formulá-la. Considero a tradução de Schuld por "falta" como mais acertada porque mantém o sentido ontológico-existencial intencionado pelo autor de Ser e Tempo.

11. Numa outra passagem de Ser e Tempo (1967, p. 284) Heidegger deixa claro mais uma vez que esta tríplice dimensão é constituída pela faticidade como estar lançado (Faktizität als Geworfenheit), pela existência como projeto (Existenz als Entwurf) e pela decadência (Verfallen). Portanto, faz parte do sentido normativo do cuidado, também uma dimensão constituída pela sua ocupação com as coisas que estão à sua mão.

12. "O clamor da consciência encontra sua possibilidade ontológica no fato de que em sua estrutura fundamental o ser-aí é cuidado” (Heidegger, 1967, p. 277-278). 


\section{Referências bibliográficas}

FIGAL, G. Metaphysik und Hermeneutik. In: Wenzel, U.J. (Hrsg.). Vom Ersten und Letzten: Positionen der Metaphysik in der Gegenwartsphilosophie. Frankfurt am Main: Fischer, 1998. p. 99-109.

FIGAL, G. Martin Heidegger: fenomenologia da liberdade. Rio de Janeiro: Forense Universitária, 2005.

FRANK, M. Selbstbewusstsein und Selbsterkenntnis. Stuttgart: Reclam, 1991.

FREITAG, B. Piaget: encontros e desencontros. Rio de Janeiro: Tempo Brasileiro, 1985.

HABERMAS, J. Wahrheit und Rechtfertigung: Philosophische Aufsätze. Frankfurt am Main: Suhrkamp, 1999.

HEIDEGGER, M. Sein und Zeit. Tübingen: Max Niemeyer, 1967.

LAJONQUIÈRE, L. Piaget: notas para uma teoria construtivista da inteligência. Revista de Psicologia da USP, São Paulo, v. 8, n. 1, p. 131-142, 1997.

LOPARIC, Z. Winnicot e o pensamento pós-metafísico. Revista de Psicologia da USP, São Paulo, v. 6, n. 2, p. 39-61, 1995.

LOPARIC, Z. Sobre a responsabilidade. Porto Alegre: EDIPUCRS, 2003. MARQUARD, O. Apologie des Zufälligen. Stuttgart: Reclam, 1996.

PIAGET, G. O julgamento moral na criança. São Paulo: Mestre Jou, 1977.

PÖGGELER, O. Heidegger in seiner Zeit. München: Fink, 1999.

STEIN, E. Seminário sobre a verdade: lições preliminares sobre o parágrafo 44 de Sein und Zeit. Petrópolis: Vozes, 1993.

TAYLOR, C. Argumentos filosóficos. São Paulo: Loyola, 2000.

YOUNISS, J. Soziale Konstruktion und psychische Entwicklung. Frankfurt am Main: Suhrkamp, 1994. 